\title{
The Effectiveness or Efficacy of Modified Nursing Interventions Classification (NIC) in Reducing the Severity of Depression among Patients with Myocardial Infarction
}

\author{
Suriya Nisar¹, Abu Talib², Iftikhar Haider Naqvi², Jawahar Lal ${ }^{3}$ \\ ${ }^{1}$ Shaheed Mohtarma Benazir Bhutto Medical University, Larkana, Pakistan \\ ${ }^{2}$ Dow University of Health Sciences, Karachi, Pakistan \\ ${ }^{3}$ Medical Unit-III, Civil Hospital, Karachi, Pakistan \\ Email: suriya.nisar@gmail.com,dr.abutalibchk@gmail.com,drihnaqvi@gmail.com,dr.jawahar811@gmail.com
}

How to cite this paper: Nisar, S., Talib, A., Naqvi, I.H. and Lal, J. (2017) The Effectiveness or Efficacy of Modified Nursing Interventions Classification (NIC) in Reducing the Severity of Depression among Patients with Myocardial Infarction. Open Journal of Psychiatry, 7, 103-114.

https://doi.org/10.4236/ojpsych.2017.72010

Received: February 17, 2017

Accepted: April 27, 2017

Published: April 30, 2017

Copyright (c) 2017 by authors and Scientific Research Publishing Inc. This work is licensed under the Creative Commons Attribution International License (CC BY 4.0).

http://creativecommons.org/licenses/by/4.0/

\begin{abstract}
Background: Post myocardial infarction depression is common and puts a negative effect on recovery. Modified Nursing interventions effectively reduce the frequency and severity of depression in such patients. Objective: The study aimed to determine the effectiveness of Modified Nursing Interventions Classification (NIC) in reducing the severity of depression among patients with Myocardial Infarction. Methods: Sixty-eight stable patients with myocardial infarction ( $>1$ month history) having mild to moderate depression in accordance to Patient Health Questionnaire-9 (PHQ-9) [with a score of 5 to 14] were enrolled. Patients were assorted into interventional and control group. Modified Nursing Intervention was offered in Interventional Group. The frequency and effectiveness of Modified Nursing Intervention among the groups were determined and compared. Results: Both moderate and mild level depression was decreased in Intervention Group as compare to Control Group. Baseline mean depression PHQ-9 score was 2.35 point statistically significantly higher in the Control Group than Interventional Group $(<0.001)$. After three weeks intervention the mean depression PHQ-9 score was 4.76 points significantly lower in Intervention Group than Control Group $(<0.001)$. Conclusion: Modified Nursing intervention is effective in reducing the frequency and severity of depression compared to routine care in patients with Myocardial infarction.
\end{abstract}

\section{Keywords}

Modified Nursing Intervention Classification, Depression, Myocardial Infarction 


\section{Introduction}

Depression has over the years become an awfully common social disaster throughout the world [1]. It is associated with many chronic (non-communicable) diseases especially those of cardiovascular origin, like myocardial infarction [2] [3]. Depression imparts grave effects on physical, mental, economic, social and personal life, which severely affects the life quality of patients [4] [5] [6]. Prevalence of depression in the general population is about $2 \%-9 \%$, among primary care patients, $5 \%-10 \%$ and $10 \%-14 \%$ among patients with medical illness in- patients [3] [7]. Worldwide, an estimated 121 million people currently suffering from depression [8] [9]. It is expected that by 2020, depression and cardiovascular diseases will be the two major causes of economic encumber world over [10] [11]. Depression during MI increases the severity and complications. If depression is not treated, then on average the lives of these patients may be shortened by ten to fifteen years in comparison to undepressed patients [12]. The research indicates that patients with cardiac disorders suffer from high depressive issues in Pakistan. In a survey in Pakistan it was found that $47 \%$ patients were observed as depressed [13] [14].

Nursing Intervention Classification (NIC) is being used in primary to tertiary care settings independently and collaboratively through direct and indirect care to the individuals, families, groups and communities all over the world [15]. It has been proved that the depressed patients can be helped by nurses using NIC [16]. Effects of NIC to reduce depression have emerged in the United States of America, China, Taiwan and Iran etc. but in Pakistan this intervention is still to be applied effectively [17] [18].

The nursing personnel using nursing intervention can take better care of depressed patients suffering from cardiac disorders [14] [17]. The use of multiple modified NIC for three weeks (21 days) in MI patients reduced depression compared to a control group receiving routine care. These results suggest that nursing interventions may possibly manage the physiological response to depression and improve MI risk factors, which could be an innovative therapeutic objective for the management of MI patients [18]. Different studies [19] [20] in the developed countries have came up with methods that improved socialization, induced feelings of success, reinforced to decrease mean depression scores meaningfully when used NIC among such patients. By reducing depression among MI patients using nursing intervention, an overall reduction of the depression can be achieved \& quality of life in patients having MI can also be improved [21] [22].

The hypothesis of an expected effect of the modified NIC in the reduction of frequency and severity of depression in patients with MI, could not find any research study in Local Population. Keeping in view of the dearth of research on the general and proper nursing care system in Local Population for depressed patients, the current study was conducted with an aim to test the effectiveness of nursing intervention in reducing the depression among MI patients. 


\section{Methods}

This quasi experimental study was conducted from December, 2013 to June 2014 at the medical outpatient department of the Dow University Hospital Karachi, a large tertiary care public sector hospital. Stable patients aged above 20 years with MI (>1 month history) having mild to moderate depression (PHQ-9 score 5-14), [23] [24] of either gender were included. Patients having any severe systemic illness, severe depression (PHQ-9 score $\geq 15$ ) or other psychiatric disorders before having MI, physically disabled were excluded from the study. Patients with uncontrolled diabetes, substance abuse, grade III or IV congestive heart failure, cardiomyopathy and valvular heart disease were also excluded. Two groups of the patients were arranged where one was interventional (modified nursing interventions were applied) and other was a control group (without modified nursing intervention on usual care). Ethical approval was sought by the Institutional Review Board before commencement of the study.

\subsection{Participant Groups}

A sample size of 68 was calculated using PASS software with 95\% Confidence Interval and $80 \%$ power of the test and taking pre and post-test mean $(\mu)$ PHQ-9 score 5.5, 3.21 and standard deviation (SD) 4.45, 3.46 in Interventional group and pre-test, post-test mean 9.21, 10.18 and standard deviation 5.19, 6.3 in the control group respectively. Sample collection was done by using non probability; purposive sampling technique. Total 115 participants were assessed where 68 were eligible. The first 34 patients were selected from interventional group and next 34 patients were allotted the control group. After selection, 5 cases from the intervention group and 3 from the control group were lost to follow up making a final allocation of the study to be (Interventional group $n=29$ \& Control group $\mathrm{n}=31)$.

\subsection{Patient Health Questionnaire 9 (PHQ 9)}

Depression was defined and graded in accordance to PHQ 9, which is a good validated scale for depression containing 9 items to assess all DSM-IV criteria for major depressive disorder. It also, assesses psychosocial impairment. Severity of depression rated as (minimal depression, score 1 - 4), (mild depression score 5 9), (moderate depression score 10 - 14), (moderately severe depression score 15 19 ), and (severe depression score 20 - 27). Patients with mild to moderate depression were included.

\subsection{Modified Nursing Care Intervention}

The interventional group had received modified nursing intervention, which included two hours NIC session (active listening, health education, socialization enhancement, self-esteem enhancement and Meditation facilitation activities). It was followed by three weeks home based practice using a patient guide tool kit (A patient guide booklet, MP3, led pencil, rubber, sharpener, patient ID Tag, in a paper bag). Patient's guide booklet; consists of information regarding method of 
meditation, certain foods to reduce depression, along with recipes (Juice and salad) and maintenance of a daily diary. This consists of sea waves and natural sounds.

Additionally, the six sound tracks; ya-Haleem, La-ilaha-IL-Allah, Bismillah, Allah-Allah, $\mathrm{Hu}$ and Salawat) was made available to the Muslim participants. Timely trigger was made possible through mobile messages and telephonic instructions by a researcher. The control group was instituted with all similar verbal instructions but was not given patient guide tool kit, messages and telephonic instructions. An assessment was carried out using pretest and post-test in both groups at three weeks interval using PHQ-9 in an Urdu version, which is available online at The Improving Access to Psychological Therapies (IAPT) [25].

\subsection{Statistical Analysis}

Data was collected on demographic variable like name, age, gender, marital status, type of family, education, language, religion. The medical comorbids like hypertension, stroke, diabetes, and type of diabetes, types of MI and past history of surgery were also collected. Blood pressure (both systolic and diastolic) and heart rate were recorded. Data was also collected on the NIC practiced by the interventional group patients.

Data was fed and analyzed through IBM, SPSS Statistical Version 21. The frequency and percentages were estimated for all qualitative variables like gender, marital status and education. Continuous variables like age and PHQ-9 score was represented by mean $\pm \mathrm{SD}$. Chi square test was applied to examine the association between two categorical variable and students t-test was applied to detect the statistical difference in reduction of scores of depression within \& between the groups, taking $p$ value $\leq 0.05$ as significant.

\section{Results}

Table 1 describes the comparison of baseline socio-demographic characteristics of all patients of both groups (Intervention and control group). It was found that the majority of patients in both groups were of age $51-60 \&>60$ years categories. Although, there seems a difference in percent distribution of ages of patients in two groups however; the difference was not statistically significant ( $p$ value $=0.531)$. Likewise; most of patients in both groups were married (Table 1 ). There was statistically significant ( $p$ value $=0.119$ ) difference between type of family among the groups. Similarly, language $\&$ religion differences among the two groups remained statistically insignificant (Table 1). Furthermore, gender difference shown in Figure 1 and difference of educational level shown in Figure 2 is statistically non-significant ( $p$ values $=0.0065 \& 0.515$ respectively). Thus, the socio demographic variables between the two groups were not so different.

Looking at comorbids and basic clinical characteristics between intervention and control groups shown in Table $2 \&$ Table 3 respectively; it is notable that 
Table 1. Baseline socio-demographic parameters of interventional \& control group.

\begin{tabular}{ccccccc}
\hline $\begin{array}{c}\text { Socio-demographic } \\
\text { parameters }\end{array}$ & $\begin{array}{c}\text { Intervention group } \\
\mathbf{n}=29\end{array}$ & $\begin{array}{c}\text { Control group } \\
\mathbf{n}=31\end{array}$ & $\begin{array}{c}\text { Pearson } \\
\text { Chi-square }\end{array}$ & $\begin{array}{c}p \text {-value } \\
\text { (2-tailed) }\end{array}$ \\
\hline Age (Years) & $\mathbf{n}$ & $\%$ & $\mathbf{n}$ & $\%$ & & \\
$<51$ years & 7 & 24.1 & 6 & 19.4 & & \\
51 - 60 years & 9 & 31.0 & 14 & 45.2 & 7.392 & 0.531 \\
$>61$ years & 13 & 44.8 & 11 & 35.5 & & \\
& 2 & Marital Status & & & \\
Divorced/separated & 6.9 & 0 & 00 & & $0.137^{*}$ \\
Married & 27 & 93.1 & 31 & 100 & & \\
& & Type of family & & & \\
Nuclear & 11 & 37.9 & 18 & 58.1 & & \\
Joint & 18 & 62.1 & 13 & 41.9 & & 0.119 \\
\hline
\end{tabular}

*Fisher's exact test.

Table 2. Frequency of comorbids among intervention and control group.

\begin{tabular}{|c|c|c|c|c|c|c|}
\hline \multirow{2}{*}{ Clinical Parameters } & \multicolumn{2}{|c|}{$\begin{array}{l}\text { Intervention group } \\
\quad \mathrm{n}=29\end{array}$} & \multicolumn{2}{|c|}{$\begin{array}{c}\text { Control group } \\
n=31\end{array}$} & \multirow{2}{*}{$\begin{array}{l}\text { Pearson } \\
\text { Chi-square }\end{array}$} & \multirow{2}{*}{$\begin{array}{c}p \text {-value } \\
\text { (2-tailed) }\end{array}$} \\
\hline & $\mathrm{N}$ & $\%$ & $\mathrm{n}$ & $\%$ & & \\
\hline Hypertension & 16 & 55.2 & 21 & 67.7 & 1.001 & 0.317 \\
\hline Stroke & 1 & 3.4 & 0 & .0 & & $0.483^{*}$ \\
\hline Diabetes Mellitus & 14 & 48.3 & 12 & 38.7 & 0.558 & 0.455 \\
\hline Type I & 4 & 28.6 & 4 & 33.3 & & \\
\hline Type II & 10 & 71.4 & 8 & 66.7 & 1.120 & $0.563^{\circ}$ \\
\hline
\end{tabular}

Myocardial Infarction

\begin{tabular}{ccccccc} 
Non-STEMI & 11 & 37.9 & 4 & 12.9 & $\mathbf{5 . 0 0 6}$ & $\mathbf{0 . 0 2 5}$ \\
STEMI & 18 & 62.1 & 27 & 87.1 & & \\
$\begin{array}{c}\text { Past history of } \\
\text { Cardiac Surgery }\end{array}$ & 10 & 34.5 & 8 & 25.8 & $\mathbf{0 . 5 3 7}$ & $\mathbf{0 . 3 2 6}$ \\
\hline
\end{tabular}

STMI ST segment elevation myocardial infarction. *Fisher's Exact Test.

Table 3. Baseline clinical Parameters of intervention and control group.

\begin{tabular}{|c|c|c|c|c|c|c|}
\hline \multirow{2}{*}{$\begin{array}{c}\text { Clinical } \\
\text { Parameters }\end{array}$} & \multicolumn{2}{|c|}{$\begin{array}{l}\text { Intervention group } \\
\qquad n=29\end{array}$} & \multicolumn{2}{|c|}{$\begin{array}{l}\text { Control group } \\
\qquad \mathrm{n}=31\end{array}$} & \multirow{2}{*}{$\begin{array}{l}\text { Independent } \\
\text { Samples Test }\end{array}$} & \multirow{2}{*}{$\mathrm{p}$-value } \\
\hline & Mean & $\begin{array}{c}\text { Std. } \\
\text { Deviation }\end{array}$ & Mean & $\begin{array}{c}\text { Std. } \\
\text { Deviation }\end{array}$ & & \\
\hline $\begin{array}{c}\text { Heart rate } \\
\text { (beats/minute) }\end{array}$ & 77.79 & 6.76 & 78.90 & 5.55 & -0.697 & 0.489 \\
\hline $\begin{array}{l}\text { Systolic BP } \\
(\mathrm{mm} \text { of } \mathrm{Hg})\end{array}$ & 140.41 & 24.22 & 144.51 & 22.03 & -0.687 & 0.495 \\
\hline $\begin{array}{c}\text { Diastolic BP } \\
(\mathrm{mm} \text { of } \mathrm{Hg})\end{array}$ & 84.48 & 11.38 & 90.00 & 8.16 & -2.168 & 0.034 \\
\hline
\end{tabular}




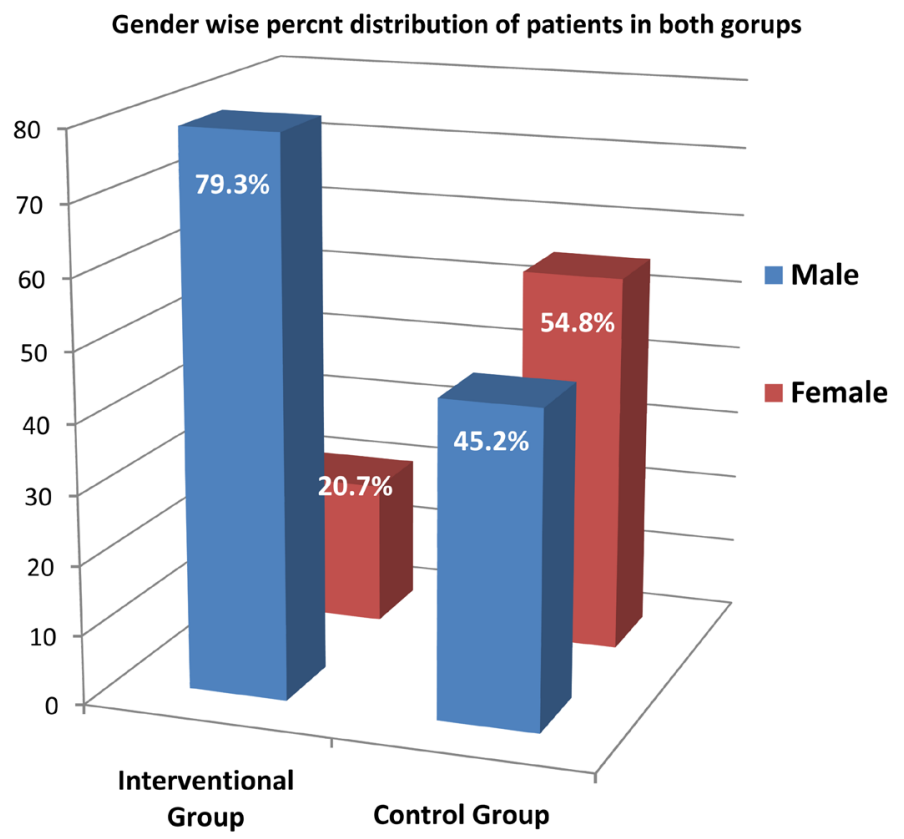

Figure 1. Gender wise percent Distribution of patients in both groups. Pearson Chisquare $=7.391 ; \mathrm{P}$-value $(2$-tailed $)=0.0065$.

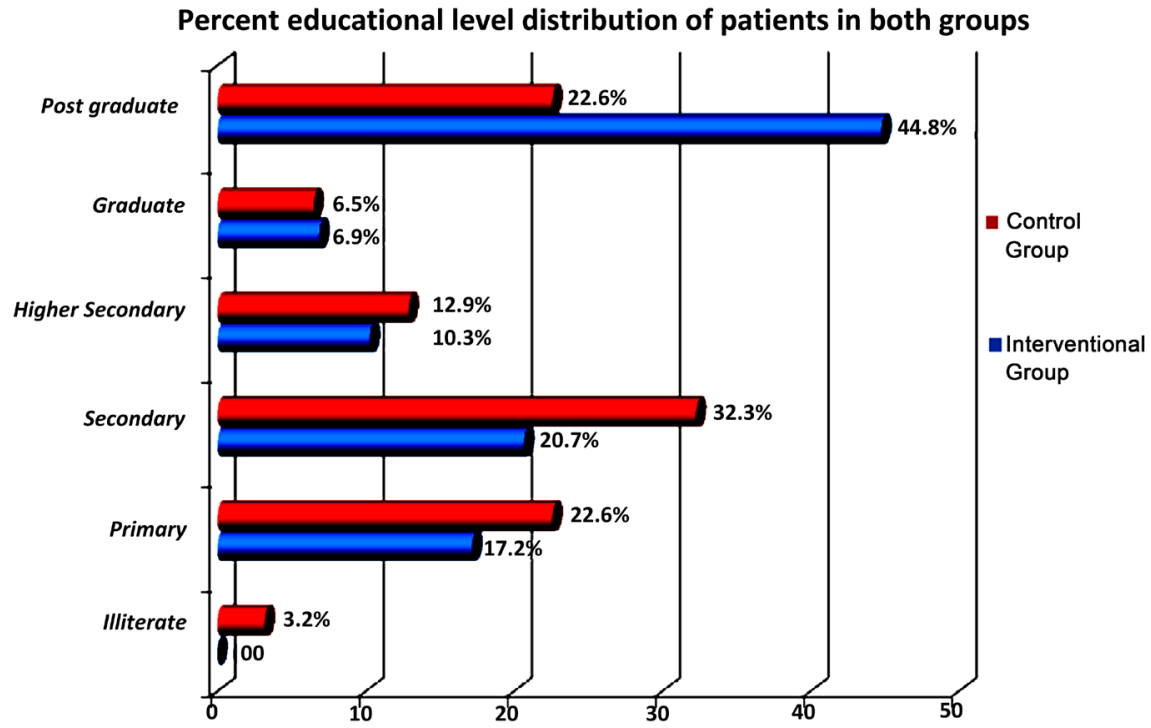

Figure 2. Percent educational level distribution of patients in both groups.

the only significant difference was in frequency \& type of MI. Accordingly, the intervention group was comprised of $62.1 \%$ patients of Acute STEMI while in control group such patients were up about $87.1 \%(p$ value $=0.025)$. Otherwise; the two groups almost resembled regarding comorbids conditions like hypertension, stroke, diabetes Mellitus, history of surgery and vitals (Heart rate, systolic \& diastolic BP) (Table 2 \& Table 3).

The main outcome of the study showed that at 21 days follow up after intervention with modified NIC, there was a significant decrease (>90\%) of frequency of patients in moderate (PHQ-9 score 10 - 14) level of depression [from 79.3\% 
$(\mathrm{n}=23)$ to only $6.9 \%(\mathrm{n}=2)$ ]. Simultaneously; $50 \%$ decrease was also noted in mild depression (PHQ- 9 score 5 - 9) patients. In post-intervention, the majority of these patients $[82.2 \%(n=24)]$ had only minimal depression (PHQ- 9 score 1 - 4). These findings were statistically significant ( $p$ values $=0.022 \&<0.001$ respectively; Table 4).

Compared to this, the control group showed half, a decrease (50\%) in the frequency of moderate level depression [from $45.2 \%(n=14)$ to $22.6 \%(n=7)$ ] while there was a $33 \%$ increase noted in mild depression patients [from $51.6 \%$ (n $=16)$ to $77.4 \%(\mathrm{n}=24)]$. Both these findings were statistically significant ( $\mathrm{p}$ values $=0.022 \&<0.001$ respectively). This difference proves the hypothesis to be correct that modified NIC is effective in the reduction of frequency and severity of depression in patients with myocardial infarction (Table 4).

Above findings were supported by intra group assessment of difference of PHQ-9 score. Within the intervention group, the mean \pm SD baseline PHQ-9 score was $11.86 \pm 2.54$ which decreased up to $3.62 \pm 2.66$ ( $p$ value $=<0.001)$ at 3 weeks follow up. Contradictory to those in the control group, the mean $\pm \mathrm{SD}$ baseline PHQ-9 score decreased from $9.51 \pm 2.21$ to only $8.38 \pm 1.85$ ( $p$ value $=<$ 0.001; Table 5). At baseline, the mean depression PHQ-9 score was 2.35 points

Table 4. Baseline and three weeks follow up frequency change in stages of depression (PHQ-9 score) among the groups.

\begin{tabular}{|c|c|c|c|c|c|c|c|c|c|c|c|c|}
\hline \multirow{3}{*}{$\begin{array}{c}\text { Frequency } \\
\text { change }\end{array}$} & \multicolumn{4}{|c|}{$\begin{array}{l}\text { Intervention group } \\
\qquad \mathrm{n}=29\end{array}$} & \multicolumn{4}{|c|}{$\begin{array}{l}\text { Control group } \\
\qquad n=31\end{array}$} & \multirow{2}{*}{\multicolumn{2}{|c|}{$\begin{array}{c}\text { Pearson } \\
\text { Chi-square }\end{array}$}} & \multirow{2}{*}{\multicolumn{2}{|c|}{$p$-value }} \\
\hline & \multicolumn{2}{|c|}{$\mathbf{N}$} & \multicolumn{2}{|c|}{$\%$} & \multicolumn{2}{|c|}{$\mathbf{N}$} & \multicolumn{2}{|c|}{$\%$} & & & & \\
\hline & $\begin{array}{l}\text { Pre } \\
\text { Test }\end{array}$ & $\begin{array}{l}\text { Post } \\
\text { Test }\end{array}$ & $\begin{array}{l}\text { Pre } \\
\text { Test }\end{array}$ & $\begin{array}{l}\text { Post } \\
\text { Test }\end{array}$ & $\begin{array}{l}\text { Pre } \\
\text { Test }\end{array}$ & $\begin{array}{l}\text { Post } \\
\text { Test }\end{array}$ & $\begin{array}{l}\text { Pre } \\
\text { Test }\end{array}$ & $\begin{array}{l}\text { Post } \\
\text { Test }\end{array}$ & $\begin{array}{l}\text { Pre } \\
\text { Test }\end{array}$ & $\begin{array}{l}\text { Post } \\
\text { Test }\end{array}$ & $\begin{array}{l}\text { Pre } \\
\text { Test }\end{array}$ & $\begin{array}{l}\text { Post } \\
\text { Test }\end{array}$ \\
\hline $\begin{array}{l}\text { Minimal } \\
\text { depression } \\
(1-4)\end{array}$ & 0 & 24 & 0.0 & 82.8 & 1 & 0 & 3.2 & 0.0 & & & & \\
\hline $\begin{array}{c}\text { Mild } \\
\text { depression } \\
(5-9)\end{array}$ & 6 & 3 & 20.7 & 10.3 & 16 & 24 & 51.6 & 77.4 & 7.67 & 43.09 & 0.022 & $<0.001$ \\
\hline $\begin{array}{c}\text { Moderate de- } \\
\text { pression } \\
(10-14)\end{array}$ & 23 & 2 & 79.3 & 6.9 & 14 & 7 & 45.2 & 22.6 & & & & \\
\hline
\end{tabular}

Table 5. Association of PHQ-9 score between intervention and control groups at baseline and three week follow up.

\begin{tabular}{|c|c|c|c|c|}
\hline \multirow[t]{2}{*}{ PHQ-9 } & \multicolumn{2}{|c|}{$\begin{array}{l}\text { Intervention group } \\
\qquad \mathrm{n}=29\end{array}$} & \multicolumn{2}{|c|}{$\begin{array}{l}\text { Control group } \\
\qquad n=31\end{array}$} \\
\hline & Mean & Std. Deviation & Mean & Std. Deviation \\
\hline Baseline & 11.86 & 2.54 & 9.51 & 2.21 \\
\hline Three weeks follow up & 3.62 & 2.66 & 8.38 & 1.85 \\
\hline Independent Samples t- Test & \multicolumn{2}{|r|}{3.812} & \multicolumn{2}{|r|}{-8.083} \\
\hline$p$-value & \multicolumn{2}{|r|}{$<0.001$} & \multicolumn{2}{|r|}{$<0.001$} \\
\hline
\end{tabular}


higher in the intervention group than controls. After three weeks intervention the mean depression PHQ-9 score was 4.76 points lower in the intervention group than the control group.

Table 6 shows that pre and post treatment mean difference of PHQ-9 score was statistically significant $(95 \% \mathrm{CI})$ when tested through paired t-test between both the groups ( $\mathrm{P}$ values $=<0.001$ each; Table 5 ).

\section{Discussion}

The cardiac patients, especially those who are suffering from MI are prone to deleterious effects of depression. Various studies have identified that depression is unrecognized and untreated. Major depressive disorders as the sub syndromal signs are frequent in patients with MI [3] [11] [26] [27]. The current study was conducted with the aim to evaluate the effectiveness of nursing intervention to decrease depression among MI patients as a home based care practices. These interventions were implemented using multiple NIC (active listening, teaching group self-esteem enhancement, socialization enhancement, and meditation facilitation) [14] [15] [28]. The PHQ-9 tool was utilized along with NANDA-I and NOC taxonomies to assess the effectiveness of nursing interventions [29]. In this study, five NIC interventions were applied, all showed evidence of effectiveness according to relationship of mean PHQ-9 between intervention and control groups at baseline and three weeks follows up.

Out of 68 myocardial infarction patients 29 in the interventional group and 31 in the control group completed the study and their 21 days follow-up PHQ-9 depression scale, were included in the final analysis. The study groups were similar in terms of demographic variables like age, marital condition, type of family,

Table 6. Association of mean difference of PHQ-9 Patients Depression Questionnaire change at baseline and three weeks follows up in the intervention and control groups.

\begin{tabular}{|c|c|c|c|c|c|c|c|}
\hline \multirow[t]{2}{*}{ Group } & \multirow[t]{2}{*}{ Mean } & \multirow[t]{2}{*}{ SD } & \multirow{2}{*}{$\begin{array}{c}\text { Mean } \\
\text { Difference }\end{array}$} & \multicolumn{2}{|c|}{$\begin{array}{l}95 \% \text { CI of Mean } \\
\text { Difference }\end{array}$} & \multirow{2}{*}{$\begin{array}{l}\text { Paired } \\
\text { t-Test }\end{array}$} & \multirow[t]{2}{*}{$p$-value } \\
\hline & & & & Lower & Upper & & \\
\hline \multicolumn{8}{|c|}{ Intervention Group $(n=29)$} \\
\hline $\begin{array}{c}\text { Baseline } \\
\text { PHQ9 }\end{array}$ & 11.86 & 2.54 & & & & & \\
\hline $\begin{array}{l}\text { After Three } \\
\text { weeks of } \\
\text { follow up } \\
\text { PHQ9 }\end{array}$ & 3.62 & 2.66 & 8.24 & 7.27 & 9.20 & 17.53 & $<0.001$ \\
\hline \multicolumn{8}{|c|}{ Control Group $(n=31)$} \\
\hline $\begin{array}{c}\text { Baseline } \\
\text { PHQ9 }\end{array}$ & 9.51 & 2.21 & & & & & \\
\hline $\begin{array}{l}\text { After Three } \\
\text { weeks of } \\
\text { follow up } \\
\text { PHQ9 }\end{array}$ & 8.38 & 1.85 & 1.19 & 0.52 & 1.73 & 3.814 & $<0.001$ \\
\hline
\end{tabular}

$\mathrm{CI}=$ Confidence Interval; $\mathrm{SD}=$ Std. Deviation. 
religion and no statistically significant difference was noted. Differences of gender and educational level were also statistically non-significant. Thus, overall, the study exhibited that the two groups were not significantly different, even the terms of systolic, diastolic BP and co-morbidities.

The first nursing intervention, active listening means observing carefully and attributing importance to a patient's verbal and non-verbal messages. In this study $82.2 \%$ patients listen to family and friends. The second NIC, health education means for building up and giving instruction and learning familiarity to assist voluntary adaptation of positive behavior to individuals health, communities, families or groups. The health education helps to gain knowledge and patients can modify behavior, it highlights and encourages the sphere of adverse behaviors with strong ones. In the current study, about $86 \%$ patients had maintained a daily diary, and other home based activities for 21 days through education approach. The third (NIC), self-respect augmentation is assisting a patient to enhance his/her self-worth by personal judgment. Game "magic box" was organized to boost participant's self-esteem. This activity compliance was $93 \%$ in the current study.

The fourth (NIC) Meditation facilitation means to assist a person to change his/her level of awareness by focusing on pertinent image or thought, which relaxes the patient. The twenty minutes meditation [15] was practiced in session followed by home based practice for twenty minutes twice a day. Participants verbalized that we feel relaxed and reduced the use of antihypertensive drugs with constant practice of meditation. Out of 29 intervention group participants, $24(82.2 \%)$ did 21 days meditation in the morning and evening. The fifth intervention, socialization augmentation was also proven to be effectual and broadly performed in $93 \%$ patients.

The current study used and evaluated all the five of these interventions and found that there was significant decreases of the mean PHQ-9 score and shifting of patients from moderate level depression to minimal levels. This proved that frequency and severity of depression can be minimized among the chronically ill patients especially those who have cardiac disorders. The results of the current study are similar to the other studies conducted in other regions of the world. Chung LJ, et al. used only one (NIC), home based deep breathing, and indicated that the processes of depressive symptoms decreased significantly over time $(p<$ $0.001)[30]$.

In an earlier Iranian study Sharif $\mathrm{F}$, et al. had evaluated one component of NIC (effect of group reminiscence therapy) on depression in older adults attending a day care center [31]. The average depression scores decreased significantly from $8.18 \pm 1.20$ to $7.55 \pm 1.19$. Azzolin $\mathrm{K}$, et al. gave the same taxonomy involved in patients with heart failure and proved the effectiveness of the multiple (NIC) nursing intervention [32]. The complete compliance of these activities may work effectively in refining the lifestyle and also improve the quality of life especially in cardiac patients [33]. This study enhances to the local, national and global awareness base about the effectiveness of nursing intervention for 
depression reduction. It has confirmed that nursing interventions can make a reduction in depression and improvements in quality of life for cardiac patients and also appreciated by patients.

The current study had certain limitations. First of all it was not community based study, therefore; the results cannot be inferred over the entire population. Secondly, only mild to moderate depression was focused on leaving severely depressed patients. The comorbidities were not assessed in post analysis. The overall sample size was smaller, which was due to financial and time constrains. However, this was a first study in the local context, which evaluated the nursing intervention's effectiveness in reducing depression among MI patients. The additional strength of the study was that response rates were high and the majority had attained sessions and acquired the nursing intervention.

The study warrants a multicenter randomized controlled trial with a larger sample size. Further, it is recommended by the study data, that a special nursing unit comprising of trained nursing personnel should be established in primary, secondary and tertiary healthcare levels for depressed patients, who are suffering from chronic illnesses. For this purpose, nurses working in the hospital and community setting should be trained to give special importance in providing education on various physical, mental and social problems caused by depression to improve the depressive state of cardiac patients in Pakistan.

\section{Conclusion}

The study highlights the importance of NIC interventions in reducing the frequency and severity of depression among chronically ill patients. Regarding selected socio-demographic variables, none of the variables had significant relationship with depression. The efficacy of these interventions was confirmed through improved mean scores with home based practice follow-up period recommending the nursing interventions as advantageous in patients with MI. The decreased post test score signifies the effectiveness of nursing intervention. The nursing staff should be trained in this regard.

\section{References}

[1] Qureshi, M.O., Khokhar, N. and Shafqat, F. (2012) Severity of Depression in Hepatitis B and Hepatitis C Patients. Journal of the College of Physicians and Surgeons-Pakistan, 22, 632-634.

[2] Betihavas, V., Davidson, P.M., Newton, P.J., Frost, A.S., Macdonald, O.S. and Steward, S. (2011) What Are the Factors in Risk Prediction Models for Re-Hospitalization for Adults with Chronic Heart Failure? Australian Critical Care, 25, 31-40.

[3] Thombs, B.D., Bass, E.B., Ford, D.E., Stewart, K.J., Tsilidis, K.K. and Patel, U.D. (2006) Prevalence of Depression in Survivors of Acute Myocardial Infarction. Journal of General Internal Medicine, 21, 30-38. https://doi.org/10.1111/j.1525-1497.2005.00269.x

[4] Mirza, I. and Jenkins, R. (2004) Risk Factors, Prevalence and Treatment of Anxiety and Depressive Disorders in Pakistan: Systematic Review. BMJ, 328, 794-797. https://doi.org/10.1136/bmj.328.7443.794 
[5] Snow, V., Lascher, S. and Mottur-Pilson, C. (2000) Pharmacologic Treatment of Acute Major Depression and Dysthymia. Annals of Internal Medicine, 132, 738742. https://doi.org/10.7326/0003-4819-132-9-200005020-00010

[6] Cameron, J., Worrall-Carter, L., Page, K. and Stewart, S. (2010) Self-Care Behaviours and Heart Failure: Does Experience with Symptoms Really Make a Difference? European Journal of Cardiovascular Nursing, 9, 92-100.

[7] Preveler, R., Carson, A. and Rodin, G. (2002) Depression in Medical Patients. The British Medical Journal, 325, 149-152. https://doi.org/10.1136/bmj.325.7356.149

[8] Reddy, M.S. (2010) Depression: The Disorder and the Burden. Indian Journal of Psychological Medicine, 32, 1-2. http://doi.org/10.4103/0253-7176.70510

[9] World Health Organization and Calouste Gulbenkian Foundation (2014) Social Determinants of Mental Health. World Health Organization, Geneva. www.who.int/about/licensing/copyright_form/en/index.html

[10] Reddy, M.S. (2010) Depression: The Disorder and the Burden. Indian Journal of Psychological Medicine, 32, 1-2. https://doi.org/10.4103/0253-7176.70510

[11] Davidson, K.W., Kupfer, D.J., Bigger, J.T., Califf, R.M., Carney, R.M. and Coyne, J.C. (2006) Assessment and Treatment of Depression in Patients with Cardiovascular Disease: National Heart, Lung and Blood Institute Working Group Report. Psychosomatic Medicine, 68, 645-650. https://doi.org/10.1097/01.psy.0000233233.48738.22

[12] Barth, J., Schumacher, M. and Herrmann-Lingen, C. (2004) Depression as a Risk Factor for Mortality in Patients with Coronary Heart Disease: A Meta-Analysis. Psychosomatic Medicine, 66, 802-813. https://doi.org/10.1097/01.psy.0000146332.53619.b2

[13] Dogar, I.A., Khawaja, I.S., Azeem, M.W., Awan, H., Ayub, A., Iqbal, J. and Thuras P. (2008) Prevalence and Risk Factors for Depression and Anxiety in Hospitalized Cardiac Patients in Pakistan. Psychiatry, 5, 38-41.

[14] Rahman, A.S., Aziz, A.J.Q., Siddiqui, M.A., Riaz, M. and Ali, R. (2015) Prevalence of Recognized and Unrecognized Depression among Medical and Surgical Patients in a Tertiary Care Hospital. Journal of the Pakistan Medical Association, 65, 1320 1324.

[15] Saranto, K., Kinnunen, U.M., Kivekas, E., Lappalainen, A.M., Liljamo, P. and Rajalahti, E. (2014) Impacts of Structuring Nursing Records: A Systematic Review. Scandinavian Journal of Caring Sciences, 28, 629-647. https://doi.org/10.1111/scs.12094

[16] Nanda, I. (2011) Nanda International Nursing Diagnoses: Definition and Classification. John Wiley and Sons Ltd., Hoboken, 2012-2014.

[17] Rodriguez-Gasquez, M.A., Arredonho-Holguin, E. and Herrera-Corte, R. (2012) Effectiveness of an Educational Program in Nursing in the Self-Care of Patients with Heart Failure: Randomized Controlled Trial. Revista Latino-Americana de Enfermagem, 20, 296-306. https://doi.org/10.1590/S0104-11692012000200012

[18] Mendes, K.D.S., Silveira, R.C. and Galvao, C.M. (2008) Integrative Literature Review: A Research Method to Incorporate Evidence in Health Care and Nursing. Texto \& Contex to Enfermagem, 17, 758-764. https://doi.org/10.1590/S0104-07072008000400018

[19] Chiang, K.J., Chu, H., Chang, H.J., Chung, M.H., Chen, C.H., Chiou, H.Y. and Chou, K.R. (2010) The Effects of Reminiscence Therapy on Psychological WellBeing, Depression and Loneliness among the Institutionalized Aged. International Journal of Geriatric Psychiatry, 25, 380-388. https://doi.org/10.1002/gps.2350 
[20] Masi, C.M., Chen, H.Y., Hawkley, L.C. and Cacioppo, J.T. (2011) A Meta-Analysis of Interventions to Reduce Loneliness. Personality and Social Psychology Review, 15, 219-266. https://doi.org/10.1177/1088868310377394

[21] Frasure-Smith, N., Lespérance, F., Prince, R.H., Verrier, P., Garber, R.A., Juneau, M., Bourassa, M.G., et al. (1997) Randomised Trial of Home-Based Psychosocial Nursing Intervention for Patients Recovering from Myocardial Infarction. The Lancet, 350, 473-479.

[22] Katon, W., et al. (2001) Rethinking Practioners Role in Chronic Illness: Specialist, Primary Care Physician and the Practice Nurse. General Hospital Psychiatry, 23, 138-144.

[23] Wittkampf, K.A., Naeije, L., Schene A.H., Huyser, J. and van Weert, H.C. (2007) Diagnostic Accuracy of the Mood Module of the Patient Health Questionnaire: A Systematic Review. General Hospital Psychiatry, 29, 388-395.

[24] Gilbody, S., Richards, D., Brealey, S. and Hewitt, C. (2007) Screening for Depression in Medical Settings with the Patient Health Questionnaire (PHQ): A Diagnostic Meta-Analysis. Journal of General Internal Medicine, 22, 1596-1602. https://doi.org/10.1007/s11606-007-0333-y

[25] Multicultural Mental Health Resource Centre (2017) PHQ in Different Languages. http://www.multiculturalmentalhealth.ca/clinical-tools/assessment/screening-for-co mmon-mental-disorders/phq-in-different-languages/

[26] Vieta, E., Sánchez-Moreno, J., Lahuerta, J. and Zaragoza, S. (2008) EDHIPO Group (Hypomania Detection Study Group) Subsyndromal Depressive Symptoms in $\mathrm{Pa}-$ tients with Bipolar and Unipolar Disorder during Clinical Remission. Journal of Affective Disorders, 107, 169-174.

[27] Stinson, C.K. and Kirk, E. (2006) Structured Reminiscence: An Intervention to Decrease Depression and Increase Self-Transcendence in Older Women. Journal of Clinical Nursing, 15, 208-218. https://doi.org/10.1111/j.1365-2702.2006.01292.x

[28] Bowles, K.H., Hanlon, A.L., Glick, H.A., Naylor, M.D., O’Connor and Riegel, M.B. (2011) Clinical Effectiveness, Access to and Satisfaction with Care Using a Telehomecare Substitution Intervention: A Randomized Controlled Trial. International Journal of Telemedicine and Applications, 2011, Article ID: 540138.

[29] Stinson, C.K. (2009) Structured Group Reminiscence: An Intervention for Older Adults. Journal of Continuing Education in Nursing, 40, 521-528. https://doi.org/10.3928/00220124-20091023-10

[30] Chung, L.J., Tsai, P.S., Liu, B.Y., Chou, K.R., Lin, W.H. and Shyu, Y.K. (2010) Home-Based Deep Breathing for Depression in Patients with Coronary Heart Disease: A Randomised Controlled Trial. International Journal of Nursing Studies, 47, 1346-1353.

[31] Sharif, F., Mansouri, A., Jahanbin, I. and Zare, N. (2010) Effect of Group Reminiscence Therapy on Depression in Older Adults Attending a Day Centre in Shiraz, Southern Islamic Republic of Iran. Eastern Mediterranean Health Journal, 16, 765770.

[32] Azzolin, K., Mussi, C.M., Ruschel, K.B., de Souza, E.N., de Fatima Lucena, A. and Rabelo-Silva, E.R. (2013) Effectiveness of Nursing Interventions in Heart Failure Patients in Home Care Using NANDA-I, NIC and NOC. Applied Nursing Research, 26, 239-244.

[33] Jones, E.D. (2003) Reminiscence Therapy for Older Women with Depression: Effects of Nursing Intervention Classification in Assisted Living Long-Term Care.

Journal of Gerontological Nursing, 29, 26-33.

https://doi.org/10.3928/0098-9134-20030701-07 
Submit or recommend next manuscript to SCIRP and we will provide best service for you:

Accepting pre-submission inquiries through Email, Facebook, LinkedIn, Twitter, etc. A wide selection of journals (inclusive of 9 subjects, more than 200 journals)

Providing 24-hour high-quality service

User-friendly online submission system

Fair and swift peer-review system

Efficient typesetting and proofreading procedure

Display of the result of downloads and visits, as well as the number of cited articles Maximum dissemination of your research work

Submit your manuscript at: http://papersubmission.scirp.org/

Or contact ojpsych@scirp.org 